\title{
An option pricing approach to the estimation of downside risk: A European cross-country study
}

Lakshman Alles

Department of Banking and Finance, Curtin University of Technology, GPO Box U1987, Perth 6001, Australia.

Tel: + 6189266 7811,Fax: + 6189266 3026, E-mail: Lakshman.Alles@cbs.curtin.edu.au

Received (in revised form): 31st January, 2008

Lakshman Alles is an associate professor in the Department of Finance and Banking at Curtin University of Technology, Perth, Australia.

\section{Practical applications}

The results of this study provide some useful information to investors in European markets in general, as well as to financial institutions such as investment bankers who supply financial products to investors. First, an assessment was made of the cost of downside protection in the four major European markets, based on the characteristics and historical track records of each market. Secondly, an examination was made of the time diversification effects in these markets, by examining the changes in the cost of downside protection as the investment horizon is increased from one year through to 20 years. These will serve as useful benchmarks for investors who wish to gauge the cost of insuring the downside risks in these markets and to financial institutions who create and offer investment products combined with forms of capital guarantees in these markets.

Journal of Derivatives \& Hedge Funds, Vol. 14 No. 1, 2008, pp. 31-41 (C) 2008 Palgrave Macmillan Ltd $1753-9641 \$ 30.00$

\section{Abstract}

The purpose of this paper is to undertake a comparative study of the costs of downside protection for investors in the four major European stock markets: UK, Germany, France and Italy, and to investigate the time diversification effects in these markets by examining the variation of this cost as the investment horizon is extended. The cost of downside protection and time diversification effects are investigated by examining the properties of a protective put strategy and a capital protected equity participation strategy in each country's stock market over investment horizons ranging from 1 to 20 years. Long-horizon investment outcomes are generated using a bootstrapping technique. Results indicate that the cost of downside protection differs from one country to another, but there is a common pattern of the cost decreasing as the investment horizon lengthens. In overall terms, the pattern of decreasing protection costs at longer investment horizons is consistent with the notion of the time diversification benefits of investment risk.

Journal of Derivatives \& Hedge Funds (2008) 14, 31-41. doi:10.1057/jdhf.2008.4

Keywords: downside risk; European stock markets; protective put; time diversification 


\section{INTRODUCTION — BACKGROUND}

Investors who are attracted to stock markets by the upside potential the markets offer, may at the same time wish to avoid the downside risk of investing in the stock market, if the cost of doing so is acceptable. Enjoying the upside potential and avoiding the downside risk in stock markets at an acceptable cost would be an attractive proposition to many risk-averse investors. The purpose of this study is to assess the cost of providing this downside protection in the major European markets, based on the characteristics and historical track records of those markets. The results of this study would serve as a benchmark for valuing financial products that combine stock investments with some measure of downside protection. This information would be of interest not only to investors but also to financial institutions that wish to understand the cost of creating investment products with forms of capital guarantees.

\section{TIME DIVERSIFICATION IN STOCK MARKETS}

The second purpose of this study is to examine the time diversification effects in the major European markets. Time diversification refers to the risk effects in an investment with different investment horizons. There is a general belief among investment professionals, also shared by some academics such as Malkiel, ${ }^{1}$ that the longer the investment horizon in the stock market, the lower the level of risk. This is attributed to the diversification effects of risk, where negative returns in some investment periods and positive returns in other periods average out over time. This effect is deemed to be stronger at longer investment horizons. The statistical measure of this effect is that risk as measured by the annualised standard deviation of returns is lower with longer investment horizons. Time diversification is well accepted by practitioners in the financial industry. For instance, financial advisers routinely recommend investors in younger age groups to invest more of their investment portfolios in riskier asset classes such as stocks rather than in safer bonds, but to gradually reduce the investment proportion in stocks in favour of bonds as they grow older, and as the investment horizon shortens.

But this view of risk diversification is not shared by all investment scholars. Renowned finance academics such as Paul Samuelson, ${ }^{2,3} \mathrm{Zvi}$ Bodie $^{4}$ and Robert Merton ${ }^{5}$ hold the view that the investment horizon does not matter in the estimation of risk. Their view stems from a more theoretical approach to analysing investor behaviour. The argument is that investors whose investment objectives are modelled by the expected utility maximisation theory and whose risk attitudes are represented by assumptions, such as constant relative risk aversion, should exhibit no difference in their risk attitudes whether the investment horizon is short or long because investor utility functions are independent of the investment horizon. Practitioners argue for a less theoretical approach. They point out that investor attitudes are not well represented by the theoretical utility functions and that stock returns deviate from theoretical models such as geometric Brownian motion, as they are known to be mean reverting.

Some researchers have turned to empirical analysis to understand the time diversification phenomenon in a given market. The debate on time diversification, however, is yet inconclusive because it is a debate that encompasses investors' perceptions on risk and risk attitudes as much as it is to do with the empirical behaviour of returns. ${ }^{6}$ 
Given the inconclusive status of the debate on time diversification, Bodie ${ }^{4}$ suggests the application of option pricing theory as an objective way to evaluate the benefits or otherwise of time diversification. Option pricing theory is an objective method of assessing the risk of investing in an asset because it does not require any assumptions about investors risk attitudes or utility functional forms. Bodie defines the risk of an asset as the cost of insuring a minimum rate of return in the risky asset. $\mathrm{He}$ expresses this in terms of the value of an European style put option on the asset, in a protective put context. Based on simulated data, Bodie shows that the value of a put that insures the risk-free rate of return increases with the time to expiration. He thereby concludes that there are no benefits to time diversification. Zou, however, proves that when the floor rate is less than the risk-free rate, the cost of insurance is a nonmonotonic function of the investment horizon, first increasing with time and then decreasing as the horizon further lengthens. $\mathrm{He}$ further points out that the cost of the insurance is a function of the underlying asset price volatility, the guaranteed floor rate and the investment horizon. If as Zhou points out, the cost of equity risk insurance is a nonmonotonic function of time, it would be important for investors to understand what stock market variables and what parameter values in these variables critically influence the behaviour and magnitude of the insurance cost. The objective of this paper is to apply option pricing theory in two related investment strategies, the protective put and the capital protected equity participation strategy, over a number of investment horizons, to evaluate the time diversification phenomenon in each of the four stock markets considered. A further contribution of this paper to the academic literature is that, whereas previous studies such as Zhou, ${ }^{7}$ Merrill and Thorley ${ }^{8}$ and Bodie $^{4}$ are all based on simulated data, this study uses actual market data so that the time diversification issue as it relates to the markets in question can be properly understood. The rest of the paper is organised as follows. The next section describes the data used in the study. This is followed by the Methodology in the subsequent section, and the results of the study in the penultimate section. The summary and conclusions are given in the final section.

\section{DATA}

The data used in this study have been sourced from the Datastream database of Thomson Financial Ltd. The stock market in France, Italy, Germany and UK are proxied by the Country Index computed by Datastream for each country. The monthly return of the stock market is represented by the monthly Return Index series computed by Datastream. The return series for all countries have a common end point of February 2007. The starting point of the series is January 1973, which is the earliest month for which index series for all four countries are available in Datastream. The Return Index is a total discrete return computation based on the growth of the country index from month to month and that includes the dividends paid by the constituent stocks. The monthly continuously compounded returns are then computed as the natural log of one plus the monthly discrete return.

\section{METHODOLOGY}

To examine time diversification effects, returns for holding periods of 1, 5, 10 and 20 years are 
computed. One way to do this is to calculate holding period return for the index series in each market at each point of the data series for ensuing periods of 1, 5, 10 and 20 years. The holding periods computed this way would overlap, but the calendar order of returns within the holding period would be maintained and would preserve the autocorrelation structure of the returns. The shortcoming with the computation of such overlapping holding period returns, however, is that first, the holding period return observations are not independent.

Secondly, the results will be influenced by the initial values of the investing periods, so that the results cannot be generalised. An alternative approach is to calculate nonoverlapping holding period returns. The problem then is that we have increasingly fewer observations as the holding period lengthens.

To overcome these limitations and provide a sufficient number of nonoverlapping holding periods to generate a distribution of returns with long holding periods such as 10 and 20 years, we extend the data set by re-sampling the available data using a bootstrap methodology. ${ }^{10,11}$ This technique re-samples return observations randomly, imposing an assumption of independence in the return structure of returns. Academics (eg, Samuelson ${ }^{3}$ and Bodie ${ }^{4}$ ) argue that time diversification is driven by the nonindependence or mean reversion of stock returns, implying that in the absence of mean reversion there would be no time diversification benefits. The approach followed here corrects for the independent assumption and tries to see if a reduction in risk is still achieved, when the independence assumption is maintained.

To compute holding period returns with the bootstrap methodology, we start with the time series of monthly continuously compounded returns and randomly re-sample the monthly returns with replacement, until the number of observations needed to compute a single holding period return is obtained. For example, to obtain a single one-year holding period, 12 monthly observations are drawn and summed to make a one-year holding period return. By repeating this process 500 times, we obtain 500 samples of one-year holding period returns with randomly selected starting points. For the purpose of estimating the volatility of the holding period, the standard deviation of the 500 holding period returns is computed. This estimate of the standard deviation is used as the volatility input for calculating the put option value for an investment with that holding period with the Black-Scholes option pricing model.

\section{The protective put}

Following Bodie, ${ }^{4}$ the cost of insuring a minimum rate of return when investing in a risky asset is expressed in terms of the value of an European style put option on the asset. An amount of $\$ S$ invested in an asset that ensures a minimum annual return of $g$ over a time period of $T$ years is equivalent to buying a put option on the asset with an exercise price of $S e^{g T}$ and the value of the put option $P$ is given by the Black-Scholes valuation equation:

$$
P=-S\left[N\left(-d_{1}\right)\right]+S e^{(g-r) T}\left[N\left(-d_{2}\right)\right]
$$

where $d_{1}=\left(\left(r-g+\sigma^{2} / 2\right) / \sigma\right) \sqrt{T}$ and $d_{2}=\left(\left(r-g-\sigma^{2} / 2\right) / \sigma\right) \sqrt{T}, N\left(d_{1}\right)$ is the standard normal cumulative probability of $d_{1}$, $\sigma$ the standard deviation of annualised returns over the time to expiry, $r$ the continuously compounded annualised risk-free rate, $g$ the floor rate, and the difference between $r$ and $g$, $(r-g)$ is referred to as the concession rate: $\delta$. 
$\mathrm{Zou}^{7}$ demonstrates that when $\delta$, the concession rate is less than or equal to zero, that is when the guaranteed rate is the risk-free rate or greater, the value of the put is an increasing function of the investment horizon $T$. But when the concession rate is greater than zero, the put price is a nonmonotonic function of $T$, and is sensitive to the level of market volatility and the selected concession rate. To determine the behaviour of the put value, the value of put options on the underlying market index is computed for alternative holding periods of 1,5 , 10 and 20 years in each of the four markets, for a range of hypothetical concession rates.

\section{Capital protected equity notes}

The put-call parity relationship can be used to show how the protective put strategy discussed above can be re-formulated in terms of a class of financial products known as capital protected equity notes or PENs, and how the cost of such products can be computed. PEN is a generic term given to a class of products that are offered by financial institutions with slight variations in form. The nature of these products is that they guarantee the protection of the initial capital (or a minimum return on capital) while allowing a limited participation in the upside of the share market, benchmarked to a share market index or a basket of shares. ${ }^{12}$ In this study, we assume the investment is in the stock market index of the respective countries examined.

According to put-call parity the protective put $(P+S)$ is equivalent to a call option, $C$ on the same underlying asset plus an investment in the risk-free asset equal to the present value of the strike price $(X)$, as shown below.

$$
P+S=C+P V(X)
$$

Applying this concept to a PEN, if the initial investment is $\$ S$, to ensure a minimum rate of return $g$ on the investment, the investment in the risk-free asset must be a fraction $e^{(g-r) T}$. This will provide a risk-free return of $g$ at the end of the period $T$. The remaining funds are invested on call options in the asset. In order to participate in gains in the stock price beyond the guaranteed rate $g$, the strike price is set equal to $S e^{g T}$. The price of the call based on the Black-Scholes valuation model is given by $C$, as shown below.

$$
C=S\left[N\left(d_{1}\right)\right]-S e^{(g-r) T}\left[N\left(d_{2}\right)\right]
$$

Table 1: Summary statistics of monthly returns

\begin{tabular}{lcccc}
\hline & France & Italy & Germany & UK \\
\hline Data span & $1973: 02-2007: 02$ & $1973: 02-2007: 02$ & $1973: 02-2007: 02$ & $1973: 02-2007: 02$ \\
Observations & 409 & 409 & 409 & 409 \\
Mean return & 0.011 & 0.0108 & 0.0073 & 0.0109 \\
Standard deviation & 0.057 & 0.0763 & 0.0507 & 0.0550 \\
Median return & 0.0146 & 0.0147 & -1.024 & 0.0122 \\
Skewness & -0.824 & -0.275 & 3.826 & 0.392 \\
Kurtosis & 2.236 & 1.863 & & 9.997 \\
\hline
\end{tabular}


With an initial $1 \$$ investment, the number of calls that can be invested in is given by the ratio between the initial funds invested in the call option $1-e^{(g-r) T}$ and the cost of the call option, $C$. This is defined as the participation rate, symbolised by $p$. Therefore, $p$ is the number of call options that could be purchased with the remaining funds available.

$$
p=\frac{1-e^{(g-r) T}}{N\left(d_{1}\right)-e^{(g-r) T} N\left(d_{2}\right)}
$$

A high participation rate is indicative of the investor's ability to participate in a higher fraction of the upside gains in the stock market indexes that we examine in this study while ensuring the minimum guaranteed return $g$.

\section{RESULTS}

A comparison of the summary statistics of the return series of each market index is shown in Table 1 . The mean monthly return over the total sample period is highest in France and lowest in Germany. The return volatility is highest in Italy, followed by France, UK and Germany. The higher moments of the return distributions are quite dissimilar across the four markets, with the French, Italian and German markets showing negative skewness whereas the UK market shows positive skewness. The UK market shows high kurtosis and tail thickness, indicating a concentration of extreme observations in the tails. In a mean variance context, the UK market has performed best with a coefficient of variation of 0.1982 , followed by France with a corresponding value of 0.193 , Germany with 0.1440 and Italy with 0.1415 .

To get a sense of the predictability of returns in each market, the autocorrelation of the return series with up to five lags are reported in Table 2. The French market reports the largest first lag autocorrelation of 0.118 followed by lower values in UK, Germany and Italy. The Italian market has the unusual feature of a higher autocorrelation at the third lag than at the first lag. The Ljung-Box Q-Statistic, however, is only significant in the case of Germany with a $p$-value of 3 per cent.

Table 3 reports the comparative costs of a put option on the market index assumed to have a value of $\$ 1$ in each market for the holding periods of 1, 5, 10 and 20 years, and for concession rates that vary from zero to 0.05 in increments of 0.01 . These are reported in panels A, B, C and D, respectively, along with the annualised standard deviation for the particular holding period, which was used as an input to Black-Scholes model for the put value calculation.

Table 2: Autocorrelations of series

\begin{tabular}{llllllr}
\hline Lag & 1 & \multicolumn{1}{l}{ 2 } & 3 & \multicolumn{1}{l}{4} & \multicolumn{1}{l}{5} & Ljung-Box Q-Stat $^{a}$ \\
\hline France & 0.118 & -0.023 & 0.064 & -0.006 & 0.085 & $44.5832(0.28)$ \\
Italy & 0.001 & -0.059 & 0.145 & -0.013 & 0.020 & $47.096(0.204)$ \\
Germany & 0.085 & 0.028 & 0.070 & -0.026 & -0.008 & $58.31(0.030)$ \\
UK & 0.095 & 0.012 & 0.029 & -0.002 & -0.081 & $36.05(0.64)$ \\
\hline
\end{tabular}

${ }^{\mathrm{a}}$ Significance level is shown in parenthesis. 
Table 3: The cost of a put option on investments with different holding periods

\begin{tabular}{lllll}
\hline & France & Italy & Germany & UK \\
\hline $\begin{array}{l}\text { Panel } A \text { - One year investment horizon } \\
\text { Volatility (standard deviation }\end{array}$ & & & & \\
of annualised returns) & 0.20045 & 0.26089 & 0.20054 & 0.20127 \\
& & & & \\
Concession rate & & & & 0.08016 \\
0.00 & 0.07983 & 0.10379 & 0.07987 & 0.07489 \\
0.01 & 0.07456 & 0.09837 & 0.07460 & 0.06986 \\
0.02 & 0.06954 & 0.09316 & 0.06957 & 0.06507 \\
0.03 & 0.06475 & 0.08815 & 0.06479 & 0.06053 \\
0.04 & 0.06021 & 0.08333 & 0.06025 & 0.05621
\end{tabular}

Panel B - Five year investment horizon

Volatility (standard deviation

0.08970

0.11720

0.07652

0.08527

of annualised returns)

Concession rate

$\begin{array}{lllll}0.00 & 0.07988 & 0.10425 & 0.06818 & 0.07595 \\ 0.01 & 0.05595 & 0.07915 & 0.04494 & 0.05224 \\ 0.02 & 0.03772 & 0.05880 & 0.02810 & 0.03444 \\ 0.03 & 0.02443 & 0.04268 & 0.01660 & 0.02171 \\ 0.04 & 0.01515 & 0.03025 & 0.00923 & 0.01305 \\ 0.05 & 0.00899 & 0.02090 & 0.00482 & 0.00746\end{array}$

Panel $C-$ Ten year investment horizon

Volatility (standard deviation

0.06522

0.08638

0.05773

0.06331

of annualised returns)

Concession rate

$\begin{array}{lllll}0.00 & 0.08213 & 0.10864 & 0.07273 & 0.07974 \\ 0.01 & 0.03962 & 0.06270 & 0.03179 & 0.03760 \\ 0.02 & 0.01641 & 0.03325 & 0.01140 & 0.01508 \\ 0.03 & 0.00574 & 0.01609 & 0.00328 & 0.00505 \\ 0.04 & 0.00168 & 0.00706 & 7.46405 \mathrm{e}-04 & 0.00139 \\ 0.05 & 4.04067 \mathrm{e}-04 & 0.00279 & 1.32115 \mathrm{e}-04 & 3.13762 \mathrm{e}-04\end{array}$

Panel D - Twenty year investment horizon

Volatility (std. deviation of annualised returns)

0.04392

0.05556

0.03953

0.04203 
Table 3: Continued

\begin{tabular}{|c|c|c|c|c|}
\hline & France & Italy & Germany & $U K$ \\
\hline \multicolumn{5}{|c|}{ Concession rate } \\
\hline 0.00 & 0.07823 & 0.09888 & 0.07043 & 0.07487 \\
\hline 0.01 & 0.01426 & 0.02667 & 0.01028 & 0.01249 \\
\hline 0.02 & 0.00123 & 0.00459 & $5.88715 \mathrm{e}-04$ & $9.17083 \mathrm{e}-04$ \\
\hline 0.03 & $4.55714 \mathrm{e}-05$ & $4.76053 \mathrm{e}-04$ & $1.15669 \mathrm{e}-05$ & $2.64297 \mathrm{e}-05$ \\
\hline 0.04 & $6.75922 \mathrm{e}-07$ & $2.84985 \mathrm{e}-05$ & $7.22859 \mathrm{e}-08$ & $2.79048 \mathrm{e}-07$ \\
\hline 0.05 & $3.87089 \mathrm{e}-09$ & $9.59305 \mathrm{e}-07$ & $1.37506 \mathrm{e}-10$ & $1.03635 \mathrm{e}-09$ \\
\hline
\end{tabular}

Results of panel A of Table 3 indicate that the volatility of the stock market, which is measured by the standard deviation of annualised returns, is in the region of 20 per cent in UK, Germany and France, and 26 per cent in Italy. Comparing put values across the columns at a one-year horizon, the cost of the put option to insure the risk-free rate (which corresponds to a zero concession rate) is correspondingly highest in the case of Italy at $\$ 0.104$, and is in the range of $\$ 0.07$ to $\$ 0.08$ in each of the other three markets. This is a consequence of the high volatility in the Italian market. As the concession increases down the columns, the cost decreases. For example, in France as the concession rate increases to 0.05 the cost decreases to $\$ 0.056$.

Comparing corresponding values across the panels, the volatility becomes lower as the horizon becomes longer. Consequently, the cost of the put option generally declines as the horizon lengthens. Again looking at the case of France, at a zero concession rate it changes only marginally from $\$ 0.079$ for one year to $\$ 0.082$ and $\$ 0.078$ for 10 and 20 years. A similar mild change is evident in all other markets. But this pattern changes as the concession rate increases from 0.02 to 0.03 and beyond. At higher concession rates, the cost of the put declines as the horizon extends. This pattern is generally similar but not identical in all markets. At a 0.01 concession rate, the cost of the put in the Italian market drops from $\$ 0.098$ at a one-year horizon to $\$ 0.079$ at five years, $\$ 0.062$ at ten years and $\$ 0.027$ at 20 years. At higher concession rates (0.05) the cost of the put declines more dramatically as the horizon increases. For example in UK, at a one-year horizon the put cost is $\$ 0.056$, and this drops to $\$ 0.007$ at five years, drops to negligible levels as the horizon extends from 5 to 10 and 20 years.

The behaviour of the put cost can be understood by the fact that there are opposing factors affecting the value of the put, as noted by Zou. ${ }^{7}$ According to the Black-Scholes model, the put price decreases as the interest rate increases, or equivalently, as the present value of exercise price of the put given by $e^{(g-r) T}$ decreases. The volatility given by $\sigma \sqrt{ } T$ will be generally constant as the horizon increases. This is because $T$ the standard deviation of annualised returns will decline at the rate $1 / \sqrt{ } T$ with the horizon T. A combination of these factors can lead to a decline in put values as the horizon 
Table 4: Protective equity note participation rates at different investment horizons

\begin{tabular}{|c|c|c|c|c|}
\hline & France & Italy & Germany & $U K$ \\
\hline \multicolumn{5}{|c|}{ Panel $A$ - One year investment horizon } \\
\hline \multicolumn{5}{|c|}{ Concession rate } \\
\hline 0.01 & 0.11774 & 0.09186 & 0.11769 & 0.11729 \\
\hline 0.02 & 0.22165 & 0.17530 & 0.22156 & 0.22085 \\
\hline 0.03 & 0.31338 & 0.25110 & 0.31327 & 0.31233 \\
\hline 0.04 & 0.39438 & 0.31998 & 0.39425 & 0.39314 \\
\hline 0.05 & 0.46592 & 0.38257 & 0.46577 & 0.46455 \\
\hline
\end{tabular}

Panel B - Five year investment horizon

Concession rate

$\begin{array}{lllll}0.01 & 0.46572 & 0.38124 & 0.52044 & 0.48284 \\ 0.02 & 0.71611 & 0.61809 & 0.77205 & 0.73425 \\ 0.03 & 0.85080 & 0.76544 & 0.89353 & 0.86517 \\ 0.04 & 0.92285 & 0.85699 & 0.95154 & 0.93287 \\ 0.05 & 0.96094 & 0.91366 & 0.97868 & 0.96739\end{array}$

Panel $C-$ Ten year investment horizon

Concession rate

$\begin{array}{lllll}0.01 & 0.70605 & 0.60284 & 0.74962 & 0.71676 \\ 0.02 & 0.91699 & 0.84499 & 0.94082 & 0.92322 \\ 0.03 & 0.97832 & 0.94155 & 0.98749 & 0.98089 \\ 0.04 & 0.99494 & 0.97904 & 0.99774 & 0.99579 \\ 0.05 & 0.99897 & 0.99295 & 0.74962 & 0.99920\end{array}$

Panel D - Twenty year investment horizon

Concession rate

$\begin{array}{lllll}0.01 & 0.92709 & 0.87173 & 0.94631 & 0.93556 \\ 0.02 & 0.99627 & 0.98626 & 0.99822 & 0.99723 \\ 0.03 & 0.99990 & 0.99895 & 0.99997 & 0.99994 \\ 0.04 & 1.00000 & 0.99995 & 1.00000 & 1.00000 \\ 0.05 & 1.00000 & 1.00000 & 1.00000 & 1.00000\end{array}$

lengthens. But it was observed that this decline was different for different levels of the concession rate. The general decline in put values can be regarded as supportive of the notion of the time diversification, or in other words, the decline in risk at greater horizons.

A pertinent question is whether the option feature of PEN products available to investors in 
the market would be priced at or near the Black-Scholes price. One would expect this price to be different for at least two reasons. One is that the option feature of a PEN does not trade independently, as it is attached to the investment and cannot be expected to trade at the Black-Scholes value. Secondly, financial institutions would price PENs to make a profit; therefore, one would expect investors to pay more than the Black-Scholes value for the option feature of the PEN.

Table 4 reports the participation rates on the market index in each country when concession rates vary from zero to 0.05 in increments of 0.01 , and when the holding periods vary from 1 to 5, 10 and 20 years. These are reported in panels $\mathrm{A}, \mathrm{B}, \mathrm{C}$ and $\mathrm{D}$, respectively.

In Table 4 , the protective equity note participation rates on the market index in each market for the holding periods of 1, 5, 10 and 20 years are reported in panels $\mathrm{A}, \mathrm{B}, \mathrm{C}$ and $\mathrm{D}$, respectively. For example, the value of 0.117 for Germany at a concession rate of 0.01 for a one-year investment horizon means that an investor can ensure the guaranteed one-year return of 1 per cent below the risk-free rate and at the same time participate in 11.7 per cent of the upside potential of the stock market returns beyond the guaranteed rate. Looking across that row, the French, German and UK markets provide participation rates in the region of 11.7 per cent, whereas Italy provides the lowest with a 9.1 per cent participation rate. This is again commensurate with the differences in market volatility. Going down the columns within that panel, one can observe that investors participate more in the upside of the market if the guaranteed rate is willing to be lowered. In Italy, for example, if the concession rate is 5 per cent, the investor can enjoy a participation rate of 38.2 per cent. Going down the panels from A to D, one observes that as the investment horizon lengthens, the participation rate increases in a consistent way. For example in UK, given a 0.01 concession rate, the participation rate rises from 11.7 to 48.2 per cent, 71.7 and 93.5 per cent as the horizon lengthens from 1 year to 5, 10 and 20 years, respectively. A similar pattern is evident in the other markets.

The pattern of rising participation rates is consistent with the theoretical results of Merrill and Thorley, who based their analysis on simulated data. These results indicate a lowering of the cost of insurance as the investment horizon increases and once again support the notion of time diversification benefits.

\section{SUMMARY AND CONCLUSIONS}

The purpose of this paper was, first, to assess and compare the costs of protecting the downside risk of investing in the stock markets of UK, Germany, France and Italy. The cost of downside protection was assessed by means of a protective put strategy and a protective equity participation strategy. The second purpose of the paper was to examine the time diversification effects in these markets by examining the changes in the cost of downside protection as the investment horizon is increased from 1 year through to 20 years, using the option pricing techniques. As long horizon returns are not available due to data limitations in these markets, they were computed by utilising a bootstrapping technique.

Results showed that the Italian market had the highest cost of investment protection and correspondingly, the lowest equity participation rates, whereas the other three markets had similar cost of protection and equity participation rates. These patterns are consistent 
with the differentials in the levels of volatility across the markets. As the investment horizon was extended, results showed that the cost of protection becomes progressively lower and that this pattern of declining costs is accentuated when the concession rate is increased. Overall, these results are consistent with the notion of the time diversification benefits of investing over longer investment horizons. The results of this paper will serve as useful benchmarks not only for investors who wish to gauge the cost of insuring the downside risks in these equity markets, but also to those financial institutions who may wish to create and offer investment products combined with elements of downside protection in these markets.

\section{References and Notes}

1 Malkiel, B. (1996) 'A Random Walk Down Wall Street', W.W. Norton \& Co, New York.

2 Samuelson, P. (1963) 'Risk and Uncertainty: A Fallacy of Large Numbers', Scientia, Vol. 98, No. 2, pp. 108-113.

3 Samuelson, P. (1969) 'Life Time Portfolio Selection by Dynamic Stochastic Programming', Review of Economic Statistics (August), pp. 239-246.

4 Bodie, Z. (1995) 'On the Risk of Stocks in the Long Run’, Financial Analysts Journal (May/June), pp. 18-22.
5 Merton, R.C. and Samuelson, P. (1974) 'Fallacy of the Log-normal Approximation to Portfolio Decisionmaking Over Many Periods', Journal of Financial Economics (May), pp. 67-94.

6 Kritzman, M. (1994) 'On Time Diversification', Financial Analysts Journal (January/February), pp. $14-18$.

7 Zou, L. (1997) 'Investments With Downside Insurance and the Issue of Time Diversification', Financial Analysts Journal (July/August), pp. 73-79.

8 Merrill, C. and Thorley, S. (1996) 'Time Diversification: Perspectives from Option Pricing Theory', Financial Analysts Journal (May/June), pp. 13-19.

9 Datastream computes the country index from a constituent list of the larger stocks listed in the stock exchange representing at least 75-80 per cent of the market capitalisation in the country.

10 A description of the bootstrap re-sampling technique can be found in Efron (1979) ${ }^{11}$.

11 Efron, B. (1979) 'Bootstrap Methodology: Another Look at the Jacknife', Annals of Statistics, Vol. 7, No. 13, pp. 1-26.

12 Some examples of investment products within the category of PENs, issued by European financial institutions are: (i) Guaranteed Capital Bonds issued by Royal bank of Scotland for fixed term investments with returns linked to the FTSE $100^{\mathrm{TM}}$, invested for three and half or six years. (ii) Three or five-year protected FTSE plans, offering 200 per cent of FTSE 100 growth issued by Barclays Wealth (iii) Growth Investment Plan Plus issued by Legal \& General offering investors 160 per cent of FTSE 100 capital growth over six years plus 100 per cent capital protection at maturity. 